Gut, 1971, 12, 16-19

\title{
Abnormal lactic dehydrogenase isoenzyme patterns in ulcerative colitis with precancerous change
}

\author{
B. LEWIS, B. C. MORSON, A. W. FEBRUARY, J. HYWEL JONES, AND \\ J. J. MISIEWICZ
}

From St Mark's Hospital, London

SUMMARY The isoenzyme pattern of lactic dehydrogenase was measured in rectal biopsies from six patients with ulcerative colitis in whom precancerous histological changes had been independently recognized. There was a highly significant increase in the ratio of isoenzymes IV $+\mathrm{V}$ to I + II. This suggests that lactic dehydrogenase isoenzyme measurement may prove a valuable addition to histology in the recognition of precancer in ulcerative colitis.

Longstanding ulcerative colitis has been shown in several studies (Goldgraber, Humphreys, Kirsner, and Palmer, 1958; Slaney and Brooke, 1959; Edwards and Truelove, 1964) to predispose to carcinoma of the large bowel. Subgroups of patients have been defined who are especially at risk but only a minority develop this complication. Recently Morson and Pang (1967) have described the histological criteria of precancer in rectal biopsies from patients with ulcerative colitis, which may help to identify individuals at particular risk.

In the present study we have attempted to extend the work of Morson and Pang (1967) by seeking biochemical abnormalities which might correlate with this histological pattern. Such changes would be suitable for quantitation. There is evidence from studies of bronchial (Wieme, van Hove, and van der Straeten, 1968), colonic (Langvad, 1968), and uterine (Stagg, and Whyley, 1968) cancers and malignant cerebral tumours (Gerhardt, Clausen, Christensen, and Riishede, 1967) that the pattern of lactic dehydrogenase isoenzymes is abnormal in such tissues or in serum from affected patients. Normally there is a preponderance of isoenzymes I and II (which migrate rapidly on electrophoresis) over the slowmoving isoenzymes IV and V; in malignant tissues this may be replaced by a relative excess of the slow isoenzymes or of isoenzyme III.

We report here our findings of lactic dehydrogenase isoenzyme distribution in rectal biopsies from patients with ulcerative colitis, with and without histological evidence suggesting precancer, and in a control group.

Received for publication 29 September 1970.
Methods

Specimens of rectal mucosa were obtained by suction biopsy. They were divided into two, and one part was fixed and examined histologically by one of us (B.C.M.). Further confirmation of the histological diagnosis was obtained on surgical specimens in four patients. Histological precancer was diagnosed without prior knowledge of the biochemical findings.

The remainder of the tissue, or a weighed portion of 1.5 to $30 \mathrm{mg}$, was rinsed in ice-cold saline and homogenized in 0.1 to $0.25 \mathrm{ml}$ isotonic saline at $0^{\circ} \mathrm{C}$, using a glass-on-glass Griffith homogenizer. Electrophoresis was carried out immediately on agar gel by a method based on that of Wieme (1965). 'Noble' agar, $0.8 \% \mathrm{w} / \mathrm{v}$ in barbitone buffer 0.05 ionic strength, $p \mathrm{H} 8.6$, was used at a thickness of $1.5 \mathrm{~mm}$ on microscope slides. A slit, $15 \mathrm{~mm}$ in length, was cut $3 \mathrm{~cm}$ from the cathodal end, into which an aliquot of $5 \mu \mathrm{l}$ of the homogenate was introduced. Electrophoresis was carried out for 90 minutes at a constant potential of 120 volts without special cooling.

The isoenzymes were detected by production of a blue formazan. When electrophoresis was complete the slide was removed, and the gel covered in filter paper soaked in the following freshly mixed reagent: $3.2 \mathrm{ml}$ phosphate buffer (ionic strength $0 \cdot 1, p \mathrm{H} \mathrm{7.38)} ; 0.6 \mathrm{ml}$ sodium lactate $(434 \mathrm{mg}$ in $25 \mathrm{ml}$ phosphate buffer); $0.6 \mathrm{ml} \beta$-nicotinamide adenine dinucleotide $(50 \mathrm{mg}$ in $5 \mathrm{ml}$ distilled water); $1.8 \mathrm{ml}$ M.T.T. tetrazolium ( $25 \mathrm{mg}$ in $25 \mathrm{ml}$ distilled water); and $0.2 \mathrm{ml}$ phenazine methosulphate $(10 \mathrm{mg}$ in $10 \mathrm{ml}$ ) prepared freshly. The covered slides were 
incubated in a closed container at $37^{\circ} \mathrm{C}$ for 20 minutes, then carefully washed with tap water followed by distilled water until the background was almost colourless; they were then allowed to dry under filter paper.

Scanning was carried out in the Joyce-Loebl Chromoscan densitometer. From the integral recording a ratio was calculated of the absorbances of four of the five isoenzymes ${ }^{1}$ :

\section{$\frac{\text { Area of lactic dehydrogenase IV }+\mathrm{V}}{\text { Area of lactic dehydrogenase } \mathrm{I}+\mathrm{II}}$.}

In a further aliquot of the homogenate total lactic dehydrogenase activity was assayed by the method of King (1965).

\section{Selection of Patients and Controls}

The control group consisted of 14 consecutive patients admitted for investigation of functional bowel disorders or for haemorrhoidectomy. Rectal biopsy was performed for histological examination as part of the investigation to exclude other pathology such as inflammatory bowel disease. All were found to be normal. No patient with evidence of malignant disease or polyposis was included.

Twenty-nine patients with clinical, radiological, and histological evidence of ulcerative colitis were

${ }^{1}$ Following an International Union of Biochemistry nomenclature, lactic dehydrogenase $I$ is defined as that isoenzyme migrating furthest towards the anode.

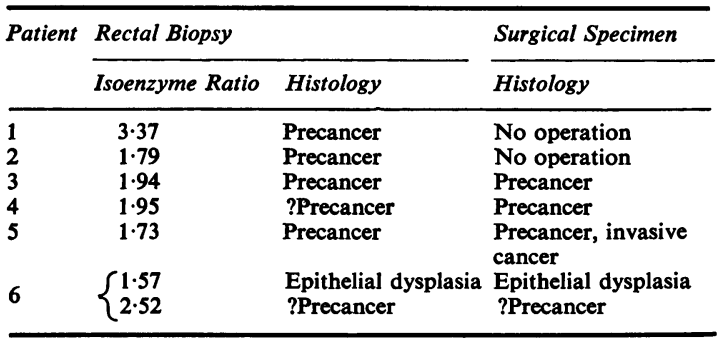

Table I Isoenzyme ratio and histological findings in precancer group studied. Of these, five had the histological criteria of precancer (Morson and Pang, 1967) and one had changes strongly suggestive of this diagnosis (Table I), 18 had total or extensive colitis but had no evidence of colonic cancer or precancer, and five had distal, uncomplicated colitis.

Rectal biopsies from three patients with Crohn's disease were also studied.

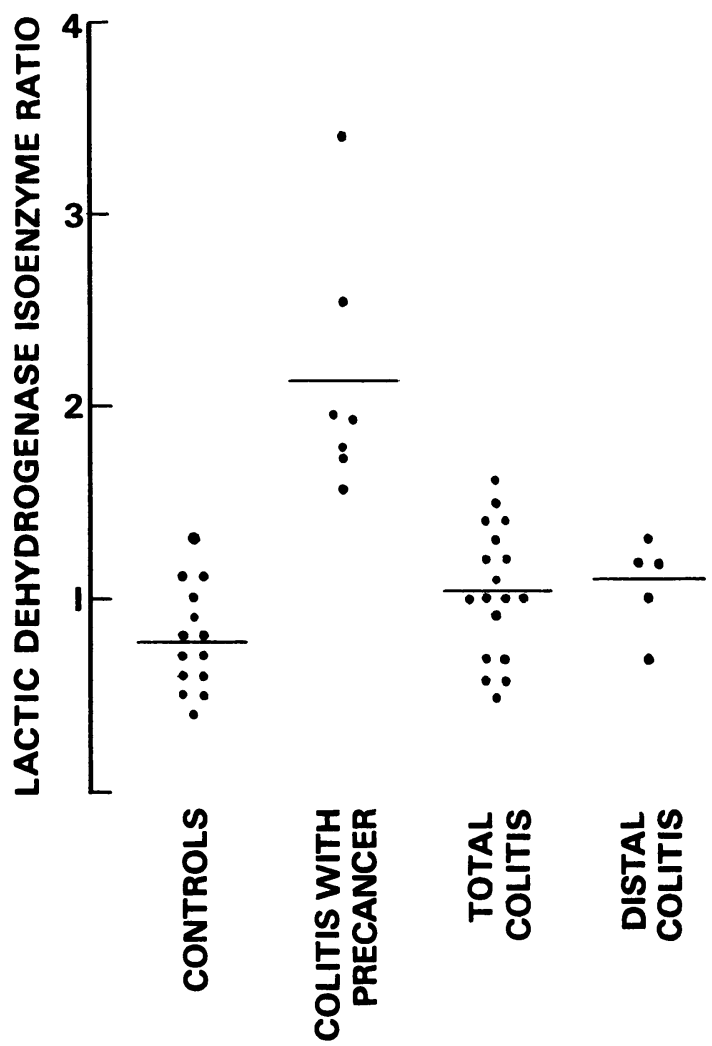

Fig. 1 Lactic dehydrogenase isoenzyme ratio $\frac{I V+V}{I+I I}$ in ulcerative colitis with and without precancerous change

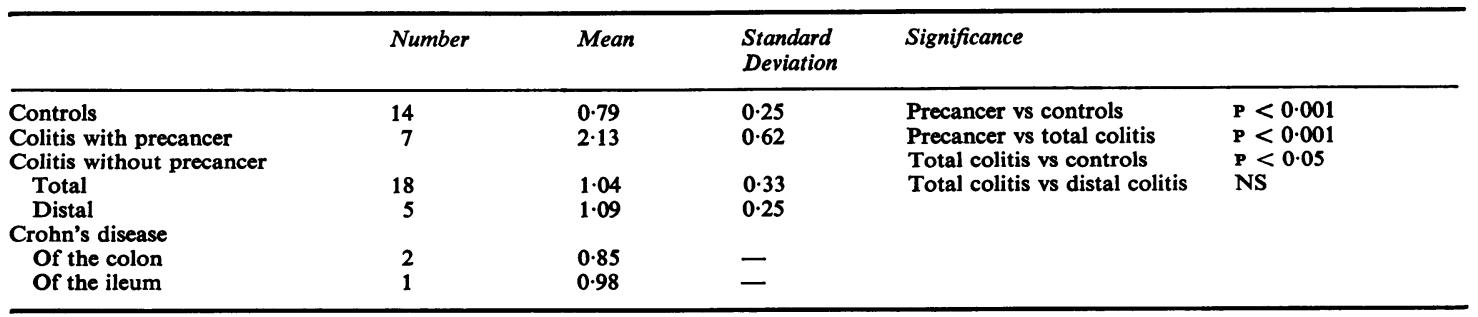

Table II Lactic dehydrogenase isoenzyme ratio $\frac{I V+V}{I+I I}$ in rectal biopsy specimens 


\section{Results}

Table II and Fig. 1 show the ratio of slow-migrating to fast-migrating lactic dehydrogenase isoenzymes in the rectal mucosa. Ulcerative colitis uncomplicated by 'precancer' was associated with a slight increase above normal in the mean lactic dehydrogenase ratio, but there was considerable overlap. Ratios of up to 1.61 were seen in this group, four out of 18 being above the mean +2 standard deviations limit of the control group. There was, however, a marked preponderance of slow-migrating isoenzymes of lactic dehydrogenase in the rectal mucosa of colitic patients with histological features of precancer (Tables I and II). The increase in isoenzyme ratio in this group was highly significant in relation both to the control series and to the colitic patients who did not have 'precancerous' rectal mucosa. Every specimen with this diagnosis had a lactic dehydrogenase isoenzyme ratio exceeding the observed upper limit of the normal range $(1 \cdot 33)$. Patient 5 (Table I) had an isoenzyme ratio of 1.73 in the rectal biopsy; subsequent colectomy revealed an invasive carcinoma of the proximal large intestine. There was no apparent relationship between the severity of the inflammatory change and the lactic dehydrogenase isoenzyme pattern.

The ratio was normal in rectal biopsy specimens from three patients with Crohn's disease.

Total lactic dehydrogenase activity in the biopsy material was $154 \pm 76 \mathrm{IU} / \mathrm{g}$ in the control group, $144 \pm 126 \mathrm{IU} / \mathrm{g}$ in total colitis, and $139 \pm 72 \mathrm{IU} / \mathrm{g}$ in distal colitis; in colitis with precancer it was $60 \pm 43 \mathrm{IU} / \mathrm{g}$ which differed significantly $(\mathrm{P}<0.01)$ from the control group but not from the colitic groups.

\section{Discussion}

The histological recognition of precancer in rectal biopsies may prove valuable in the identification of those patients with ulcerative colitis who are particularly at risk from developing invasive carcinoma. The finding that an abnormal lactic dehydrogenase isoenzyme pattern regularly accompanies this histological change is important because this enzyme pattern is also a feature of invasive carcinoma (Langvad, 1968; Stagg and Whyley, 1968). It is also seen in carcinoma in situ of the cervix (Latner, Turner, and Way, 1966). The correlation between independently observed histological and biochemical criteria of malignancy reported here lends support to the concept that a pre-invasive stage of malignant change is an entity recognizable in some patients with ulcerative colitis.

A few rectal biopsy specimens from patients with ulcerative colitis showed moderate elevation of the ratio of lactic dehydrogenase IV $+\mathrm{V}$ to $\mathrm{I}+\mathrm{II}$ without histological precancer. Furthermore, the mean ratio in both groups of patients with colitis but without histological precancer was somewhat higher than in normal rectal mucosa. It is possible that the presence of inflammatory disease alone or consequent reactive hyperplasia of epithelium are associated with some change in isoenzyme ratio, perhaps reflecting adaptation to hypoxia; for example, this has been reported in the inflamed appendix (Plucnar, Kamaryt, and Dluhos, 1967). However, lactic dehydrogenase isoenzyme patterns in the serum of 16 patients with ulcerative colitis have been reported to be substantially normal (Hendrich and Hule, 1967). Alternatively, the biochemical abnormality may represent an earlier, more sensitive measure of malignant change than the histological pattern as at present defined. Current studies of other enzymes and serial observations on patients with ulcerative colitis may help to resolve this problem.

Mean total lactic dehydrogenase activity was significantly low in precancerous mucosae in comparison with normal tissue but there was considerable overlap. Lactic dehydrogenase isoenzymes vary in some kinetic properties, eg, Michaelis constants; consequently, assay methods that are optimal for isoenzyme I may underestimate isoenzyme V. An effect of this nature may account for the apparently lower activities which accompany the shift in isoenzyme distribution.

We gratefully acknowledge the advice given by $\mathrm{Dr}$ Donald Moss and Dr John E. Lennard-Jones and the permission of the consultant staff of St Mark's Hospital to study their patients. Mr Lloyd Soodeen gave valuable technical assistance.

This investigation was supported by a grant to B.C.M. from the Cancer Research Campaign. We also wish to acknowledge help given by the MRC Gastroenterology Unit, Central Middlesex Hospital.

\section{References}

Edwards, F. C., and Truelove, S. C. (1964). The course and prognosis of ulcerative colitis. Part 3. Complications. Gut, 5, 1-22.

Gerhardt, W., Clausen, J., Christensen, E., and Rushede, J. (1967). Lactate dehydrogenase isoenzymes in the diagnosis of human benign and malignant brain tumors. J. nat. Cancer Inst., 38, 343-357.

Goldgraber, M. B., Humphreys, E. M., Kirsner, J. B., and Palmer, W. L. (1958). Carcinoma and ulcerative colitis, a clinico-pathologic study. II. Statistical analysis. Gastroenterology, 34, 840-846.

Hendrich, F., and Hule, V. (1967). Serum lactic acid dehydrogenase isoenzyme patterns in ulcerative colitis. Amer. J. Proctol., 18, 399-401.

King, J. (1965). Practical Clinical Enzymology. Van Nostrand, London. 
Langvad, E. (1968). Lactic dehydrogenase isoenzyme patterns in the tumour bearing colon. Int. J. Cancer, 3, 17-29.

La`ner, A. L., Turner, D. M., and Way, S. A. (1966). Enzyme and isoenzyme studies in preinvasive carcinoma of the cervix. Lancet, 2, 814-816.

Morson, B. C., and Pang, L. S. C. (1967). Rectal biopsy as an aid to cancer control in ulcerative colitis. III. Complications. Gut, 8, 423-434.

Plucnar, B., Kamaryt, J., and Dluhos, M. (1967). Lactic dehydrogenase heterogeneity in the inflamed appendix. Int. Surg., 47, 428-435.
Slaney, G., and Brooke, B. N. (1959). Cancer in ulcerative colitis. Lancet, 2, 694-698.

Stagg, B. H., and Whyley, G. A. (1968). Some characteristics of lactic dehydrogenase isoenzymes in tumours of the female genital tract. Clin. chim. Acta, 22, 521-533.

Wieme, R. J. (1965). Agar Gel Electrophoresis. Elsevier, Amsterdam.

W'ieme, R. J., Hove, W. Z. van, and Straeten, M. E. van der. (1968). The influence of cytostatic treatment on serum LDH patterns of patients with bronchial carcinoma and its relation to tumor regression. Ann. N.Y. Acad. Sci., 151, 213-221. 